\title{
Scientific computing to foster student research: overview and conceptual framework for STEM curricula
}

\author{
Vladimiras Dolgopolovas *, [0000-0002-0416-8930], Tatjana Jevsikova [0000-0002-6253-7941] \\ Vilnius University Institute of Data Science and Digital Technologies, Akademijos str. 4, LT-04812 \\ Vilnius, Lithuania
}

\begin{abstract}
The goal of this research is to develop a comprehensive and holistic framework focused on fostering students' scientific inquiry and research activities through scientific computing education by implementing computational experiments and simulations. The main scientific contribution of this article is a systematic approach to interdisciplinary and integrated curricula for Science, Technology, Engineering and Mathematics (STEM) education. The key interest is how to develop and apply appropriate learning resources that include software learning objects. In order to implement the goal of the research, we consistently study the problematic of developing the Technological, Pedagogical and Content Knowledge (TPACK) model for the scientific computing education domain and provide a methodology for the development and integration of relevant educational resources into the educational process. Based on this, we provide a generalized model of scientific computing education focused on scientific inquiry and research activities of students.
\end{abstract}

Keywords: teaching and learning strategies; educational issues of scientific computing; simulation based education; model based education; STEM education; Design Science Research

\section{Introduction and problem statement}

Scientific computing (SC) could become a unifying discipline for university Science, Technology, Engineering and Mathematics (STEM) education. The possible methodology is based on welldeveloped approaches like scientific inquiry (SI) and model-based simulations.

SI (in a broader sense) includes teaching how to design scientific model-based simulations (artefacts, which could be designed and evaluated using the relevant methodology) to solve specific scientific or educational problems. The unifying teaching paradigm for university STEM education can be formulated as follows: SI (research) should be taught by means of making model-based computer simulations in various fields and using seamless approach for theoretical prerequisites; The meaning of SI is universal for all disciplines; SI can be formally defined as "an activity of conducting (making and using) scientific model-based simulations".

The importance of models and model-based approaches implies from the following: (1) Theories of model-centred instruction and model-based education are well developed (Molenda et al., 2013); (2) Model as an artefact allows practical methods and analytic techniques of Design Science Research (DSR) (Dolgopolovas et al., 2019; Hevner, 2004) and model-based system analysis to be used in research and education; (3) There is a strong connection between cognitive activities (mental models) of students and activities of making (developing, programming and even using pre-developed) computer models (Landriscina, 2009); (4) Model serves as a basis for model-based simulations.

In this study, model-based simulations are positioned as a basic tool within the provided methodology due to these reasons: (1) There is a connection between mental simulations and computer simulations activities (Landriscina, 2013); (2) Simulations (of one or another type) are involved in the

\footnotetext{
* Corresponding author

e-mail: vladimiras.dolgopolovas@mif.vu.lt (Vladimiras Dolgopolovas)
} 
activity of any model development; (3) Simulation is a kind of generalization of models; (4) Simulations intersect with serious games and enable the constructionist environment and learner-centred education.

\section{Research methodology}

The problem that stimulated this research is the absence of interdisciplinarity and holistic view on scientific computing education on a university level, contributing to engineering education in particular and STEM education in general.

The goal of the research is to develop a feature model for scientific computing education (SCE) and provide the design principles for design and integration of the relevant learning resources including software learning objects (SLO) for scientific inquiry driven scientific computing.

The main research questions we aim to answer in this article are the following:

1. What is the conceptual framework for scientific inquiry fostering scientific computing education?

2. How to design and integrate educational resources aimed to teach scientific computing, with an emphasis on motivating student research?

As a methodology we use a combination of literature survey and iterative development of the model. We provide the results based on a structured and synthesised survey of an extensive number of literature sources. TPACK framework (discussed in the next section) is used to define educational, technological and content domains for scientific computing education using scientific inquiry.

In order to answer the posed research questions, we start with a study of the context specific aspects: interdisciplinarity and interdisciplinary curricula development; approaches to scientific computing education; educational technologies and model-based approaches to education; simulationcentred approach; learning objects for computer science education and the role of software program if considered as a learning object; the role of scientific inquiry and its place in engineering education. Next we move on to studying of the contents: pedagogical content domain study, including interdisciplinary aspects, aspects of scientific computing education, models of reasoning; educational content domain study including educational content design aspects; technological content study. In the parallel, we develop our own perspective on the topics and provide the relevant feature models for scientific inquiry centred pedagogy and scientific computing education in general. The main design principles of designing educational content for scientific inquiry centred scientific computing education are also provided.

\section{Implementation of TPACK model in scientific computing educational domain}

In order to systematize the content of research, the TPACK model has been implemented. The aim of this is to provide the description and specification of the content specific aspects, specifying definite feature, enabling the process of design of SLO for the SCE.

A specific view on teaching with technology is implemented. In the context of this research, teaching with technology actually transforms into teaching technology, and the technological domain is presented in the content of teaching. Both technological and content knowledge domains are intersected forming an educational environment based on the common features of both domains.

The modelling methodology is based on the TPACK framework, based on which the specification of the generalized research content can be provided as: (1) pedagogical knowledge in the form of educational theories; (2) technological knowledge and relevant educational environments; (3) $\mathrm{SC}$ curriculum for content knowledge.

\section{Specification of context domain}

One of the most important parts of the model, as well as one of the most important tasks to specify during the process of design of SLOs, is the proper understanding and specification of the features of the context. The TPACK was primarily designed as a context-unaware model. This is understandable, 
as the development of educational technology started and was primarily focused on in-door static educational environments with the teachers' role primarily seen as curriculum and instructional design developers. An ongoing process of improvement of the TPACK model towards context-aware model is taking place. The idea is to include the meaning of contextual knowledge to the model itself (Mishra, 2019). We should consider the holistic environment, taking into account more comprehensive sociotechnical issues for modelling and design.

From the pragmatist researcher point of view (the word "pragmatist" is understood as the description of a research paradigm (Collier, 2017; Goldkuhl, 2012; Peirce \& Houser, 1993)), there exist some subsets of context features (sub-contexts), which are practically important during the design process of SLOs. Such sub-contexts include: (1) interdisciplinary university education in general; (2) aspects of interdisciplinary university education in terms of interdisciplinary innovations and research; (3) aspects of SCE, including descriptions of the existing approaches to SCE in general; (4) general aspects of educational technologies focusing on the constructionist approach including educational aspects of computing; (5) model-based approaches in education. These features provide the context for formulating design principles of proper design of SLOs and proper didactic solutions, simulations in education. It is important to consider simulations not only as a technological or didactic tool but as an integral part of a learning/teaching context, including such cognitive processes as simulative reasoning and grounding; common features and intersection between computer science (CS) and SC educational domains; didactic aspects of using SLOs in SC education, including possible formalization using the DSR methodology between Computer Science and SC educational domains; didactic aspects of using SLOs in SC education, including possible formalization using the DSR methodology. The provided specification gives us a complete picture of the context and enable contextual knowledge for scientific inquiry based STEM to be developed.

\section{Pedagogical domain model}

\section{Interdisciplinary curricula: existing approaches and perspectives for enhancements}

The university curricula development is based on several domains (Holley, 2009; O'Neill et al., 2018): educational philosophy, educational paradigms; didactics and epistemological perspectives; learning outcomes and course structure; assessment principles; organization of the learning process; instruction and teaching methods; educational technology and institutional organization; limitations and perspectives.

Philosophy of education and educational paradigms may differ. It is important to indicate the assumptions for these aspects. We adopt pragmatism (Pring, 2007) and postmodernism (Boboc, 2012), given the obvious difficulties in developing interdisciplinary curricula. This attitude allows us to teach flexibility and learner-centred approaches to learning, and the importance of this is explained in the following sections. In addition, it is important to emphasize that scientific research based on post structuralism or postmodernism is universal and does not enter into a single discipline (Lattuca, 2001).

Traditionally, methods of obtaining knowledge are linear. This is applicable to a disciplineoriented curriculum. Interdisciplinary knowledge is mainly based on social and institutional solutions and is not linear in nature. It is important to arrange the curricula in such a way that various epistemological ideas cross the boundaries of the various fields of knowledge (Holley, 2009). In addition to expanding the epistemological perspectives, an interdisciplinary approach to curriculum development must take into account social, cultural and economic factors. The degrees obtained at such interdisciplinary courses could practically improve the income of students (Klein, 1999). At the same time, this clearly corresponds to previously given philosophical assumptions. Another important task is to understand the epistemic nature of interdisciplinary knowledge. It is known (Boix-Mansilla, 2010) that cognitive processes which are involved into interdisciplinary based inquiry include, besides others, and a cognitive process of building integrations where such "... integrative devices include complex explanation and a focus on multiple causes for a multifaceted phenomenon" (Holley, 2009). 
Learning outcomes and the structure of the course should be based on the consideration of the interdisciplinary nature of knowledge. Knowledge develops as part of human contact and interaction (Holley, 2009). Such interaction within the university community should be clearly indicated at the stage of curriculum development. Student learning outcomes include: flexible thinking, improved cognitive skills, tolerance for ambiguity, the ability to synthesize information, improve critical thinking skills (Spelt et al., 2009). The significant problem is that interdisciplinary knowledge is usually not sufficiently structured. It is not always possible to determine the appropriate boundaries of knowledge. Disciplines develop in their own way. Understanding and processing knowledge related to another discipline is a challenge for the student and the teacher (Newell, 2001), therefore, there is a need for non-traditional approaches to structuring an interdisciplinary course.

Assessment principles should be developed taking into account the structure of interdisciplinary knowledge. A solution (and at the same time a challenge) might arise in view of the integrative nature of interdisciplinarity. Therefore, the main skill is the ability to integrate different type of knowledge. Thus, the assessment can be based on an assessment of the improvement in the skills and cognitive abilities of students, including originality, non-traditional thinking skills, computational thinking skills (Dolgopolovas et al., 2016; Juškevičiene \& Dagiene, 2018; Wing, 2008), critical thinking skills (Horvath \& Forte, 2011; Stein et al., 2007), and problem solving ability (Mitrevski, 2019), the ability to synthesize and evaluate new information.

Organization of the learning process could be based on teamwork, students' participation in discussions of interdisciplinary teams, design and research activities. This can happen through educational units that are integrated into the existing organizational structure of the university, such as cluster or autonomous colleges, university interdisciplinary departments, centres or research institutes. At the same time, there may be non-traditional approaches, such as training communities, mass open online courses and multi-contact consortia (Newell, 2001).

Instruction and teaching methods for the interdisciplinary learning include the following processes (Holley, 2009; Klein, 1990): problem identification; definition of problem knowledge; clarification of relevant epistemological concepts; integrating interdisciplinary understanding. The nature of interdisciplinary knowledge contributes to team-oriented teaching technologies and projectbased teaching methods. At the same time, online learning methods and computer enhancements can improve students' understanding and motivation (DeZure, 2010).

Educational technology and institutional organization should be adapted for the needs of interdisciplinarity. The solution could be: interdisciplinary learning groups; interdisciplinary learning environments; interdisciplinary doctoral programs; university centre for interdisciplinary teaching and learning; training for e-technologies; alternative assessment techniques. The reason for the limitations can be: institutional constraints; complexity of interdisciplinary integration; difficulties in developing the course. Motivation and prospects can include a holistic view of knowledge and integrative learning strategies (Holley, 2009).

\section{A unifying approach for development of interdisciplinary curricula}

Educational institutions nowadays struggle for the improvement of their scientific input, thus stressing the importance of the interdisciplinary research. This allows crossing the boundaries of the traditional science and increasing competitiveness (Davies \& Devlin, 2007; Dawe et al., 2005). At the same time, there are various difficulties and obstacles in that way (Campbell, 2005). One of the most important questions to answer is whether it is possible to develop an interdisciplinary university curriculum for STEM using unifying approaches. One of the possibilities could be based on SC education.

Generally, traditions in model-based simulations are based on different paradigms, which historically came from various different scientific schools and directions. There is no universal approach to modelling and simulations from the technical perspective. Every paradigm uses its own set of background theories and assumptions. At the same time, such educational goals of simulation-based education as improvements of computational thinking, critical thinking, and problem-solving skills are quite universal (Snyder \& Snyder, 2008; Wing, 2008).

It is possible to develop an interdisciplinary university STEM curriculum based on these universal goals and focusing on SI using the model-based simulation approach. This could support a 
unification approach to teaching different sciences via looking for similarities in modelling and simulation paradigms. Such similarities could serve as bridges, which interconnect various disciplines. Another possibility for unification lies in the context of system modelling and simulation science. This approach, as opposed to traditional and based on theoretical background approach, is completely application oriented and focuses on practical solutions in various fields of applications. Experts in the field of system analysis could highlight the relevant expertise, which could be used by students. Students could incorporate this knowledge into their own simulation building activities. As to developing instructional strategies, the unifying approach could be found incorporating the modelcentred approach to instructions.

\section{Approaches to interdisciplinary instructional design}

The main aspects to be considered in the process of instructional design for the interdisciplinary curriculum are: (1) degree of interaction of people outside the same disciplinary community; (2) degree of integration between knowledge bodies relevant to disciplines; (3) the presence of a comprehensive problem, theme or topic, which stimulates interdisciplinary interaction (Holley, 2009).

The key point of the presented definition is the existence of a comprehensive problem, therefore the type of knowledge studied by the interdisciplinary curriculum is a priori by its nature. Interdisciplinarity examines issues and problems that do not exist within the disciplines (Holley, 2009), therefore it is possible that there are no available training resources. The model for instructional design should be project-oriented and research-oriented. The main task is to provide a formal instruction based on a formal approach and methods (Romiszowski, 2016, p. 4).

The presented approach to the instruction, focused on the scientific inquiry, contains only guidelines for further implementation in the process of practical instructional designing. This approach requires further investigation and is positioned as a topic for further research.

\section{Scientific computing education: The scope and definitions revisited}

The definitions of SC and SC education are going to be analysed and revised, taking into account the previously presented descriptions. First, the following definition (first modification of definition provided by Golub (Golub \& Ortega, 1993)) is proposed: "Scientific computing is a scientific discipline of conducting (designing and implementing) scientific inquiry (in the field of interest) via computer simulations." Two central meanings of the presented definition should be discussed: (1) SI and (2) computer simulations.

There is a need to revise the meaning of the scientific inquiry in order to stress the result oriented activity. Jadrich (Jadrich \& Bruxvoor, 2015) suggests defining SI as an activity of creation, testing, and refinement of scientific models. Generally, this definition corresponds well with the purpose of our studies, although the following remark should be made. Testing of models generally means in practice one or other types of simulations or computer simulations in particular. Therefore, it could be referred to the earlier presented definition of so-called "model-based" simulations (Landriscina, 2013). The revised definition is: "Scientific inquiry is an activity of conducting scientific model-based simulations". SI in the field of computing could be defined as an activity of conducting model-based computer simulations.

Actually, the presented definition could be applied for any area in which simulations could take place including multidisciplinary areas. The focus in the presented definition is the model. Consequently, SC education could be defined as an educational process in the field of SC.

The model becomes the central part under the revised definition of the SC, therefore the process of scientific activity converts here to the process of designing artefacts in general or designing computer simulations in particular. The research methodology that could be implemented is Design Science Research (DSR), which allows unifying the process of research for SC thus providing new opportunities for scientists, educators, and policymakers. The DSR cycle (Hevner, 2004), could be related to SC as follows. Environment: organizational systems (supporting infrastructure and organizational structure for simulations); technical systems (hardware, software as related to simulations); DSR (design 
appropriate models including conceptual model, mathematical model, computational model, simulation solutions and process simulations). Foundations: theories in the field of SI, theories in the field of computations and simulations.

Under the previous definitions, the main attention to teaching SC is shifted from the traditional approach like focusing on various internal parts to focusing on the overall process of DSR in general. The main teaching task could be formulated as how to teach students to conduct SI using computers. It is clear that this new paradigm also includes all steps of the previous definition but the main difference is that this new paradigm systematizes the field and provides the unified research method DSR. The aim of the educator is to develop an integrated educational environment.

\section{Abductive reasoning for discovery and innovations}

How should the learning environments be designed to enable students' creativity and discovery process? Unnatural environments, such as educational settings, should obviously be distinguished from natural environments in which learning can be based on everyday experience (Laurillard, 2013).

The task of the educator or instructional designer is to arrange the proper "grounding" of the learner to settings of such unnatural environment that can be modelled as "grounded cognition" (Barsalou, 2010). Computer simulation can be positioned as a tool for such "grounding". The theory of situated simulations (Barsalou, 2008; Pezzulo et al., 2013) provides relevant theoretical foundations for modelling students' practical activities in creating computer simulations. In practice, the concept of developing of mental models, if expressed as a progression in the development of simulations as cognitive artefacts, can provide a theoretical basis for learning based on developing simulations (Dolgopolovas et al., 2019).

The conceptual model is positioned as an intermediate in the process of the corresponding "grounding" for simulation making educational activities. The next question to consider is how mental models evolve? For example, Thagard (Thagard, 2010) considers certain forms of mental representations, such as representations based on activation of patterns of neurons populations as mental models. This cognitive approach overcomes the limitations of the "sentential" model of abduction developed by Magnani (Magnani, 1999, 2009). At the same time, this provides a theoretical basis for the model of explanatory reasoning (Peirce \& Houser, 1993) that goes beyond the process of verbal information and communication.

The next important issue to explore is how new ideas can be gained during the abduction process. Mental representations can be considered as patterns of firing in populations of neurons, and the construction of mental models can be described as a causal process of developing a chain of patterns. This allows the development of a fully multimodal neural abduction model (Thagard \& Stewart, 2011) based on a convolutional mechanism which describes the process of creativity and innovations (Thagard, 2010). At the same time, various contextual factors and the logic of circumscription (McCarthy, 1981), which evaluates previous experience, as a trigger for eliminating irrelevant transactions in such a cognitive process of formulating hypotheses and the corresponding process of abductive inference.

\section{Circumscription and abductive reasoning for the process of modelling}

How to introduce circumscription and abduction reasoning into everyday educational practice of computer-based education? This is not a trivial task, moreover, the lack of practical examples, methodological and instructional approaches motivate efforts for education without computers. As an example, the well-known computer-free education movement, which was developed by Bell et.al, could be mentioned (Bell et al., 2009). In fact, the "under the hood" motivation for this is to implicitly introduce abduction and circumscription into teaching practice. It is worth mentioning the practical approach - the model of modelling approach developed by Justi and Gilbert (Justi \& Gilbert, 2002). It describes the process of development of mental and the corresponding expressed models. The presented approach describes modelling as a multistage and non-linear process, which consists of: (1) obtaining information about an object or entity to be modelled; (2) creating a mental model of that object or entity; 
(3) choosing the right way of representing and expressing this model in an adequate form; (4) testing the model in the process of experimenting both as mental and empirical; (5) an assessment of the limitations and scope of the model.

The abduction and circumscription processes allow dividing simulation using from simulation making educational methods. As applied to the process of cognitive reasoning, focusing on the processes of circumscription and abduction, the model of modelling approach could be further developed as follows: (1) inductive reasoning enables corresponding generalizations during the propositional phase; (2) abductive reasoning in the form of grounded abduction enables the process of developing of mental models based on hypothetical model-based reasoning and relevant information which is obtainable; (3) deduction reasoning enables conceptualizations as a result of the empirical design process; (4) circumscriptive reasoning provides a set of constraints and limitations that are based on existing students' knowledge and relevant skills.

\section{Content domain model}

\section{Designing content for scientific computing education}

The simulation-based learning environment requires a systematic approach to design its content. The designer should enable a smooth pathway from the concept of the learning environment to practical solutions of problems, which students could simulate using computers. The key factor, which is important here, is to "understand the ways in which simulation can foster learning in so many different contexts" (Landriscina, 2013). An appropriate way of learning is only the way of learning by building simulations as opposed to the way of learning by using simulations.

Each of the simulation making activities such as system analyses, developing of a conceptual model, designing of a computational model, programming a simulation, conduct simulation experiments, analyse the simulation data, requires understanding, requires understanding, the ability to reason and predict and the corresponding construction of mental models in this way. Building a simulation model is a challenging task in itself; also this is a challenging task in an instructional context. The pre-knowledge of students differs. In such a case, an educator could provide a pre-programmed model for simulations and shift the educational process from simulation-making to simulation-using, which is not so effective as the previous one, but supports a "mediated" style of teaching (Laurillard, 2013) and fits the previously described teaching strategy. Generally, the role of instructional support is extremely important, as the main goal, besides training particular students' skills, is to develop students' understanding of the provided concepts. This instructional support includes (Landriscina, 2013): background information, questions, hints, explanations, exploration guides, exercises, graphing tools, planning tools. However, an important observation is that this support should be provided "on the fly" and using a seamless approach, as previously described. Therefore, the "traditional" style, which is mainly oriented to requirements for prerequisites, should be transformed to the seamless style, with instructional support provided in parallel. At the same time, such transformations will improve students' motivational factors. This concept is closely related to the concept of "microworld" introduced by Seymour Papert (Wooster \& Papert, 1982) and to the similar concept of synthetic environments (Seel $\&$ Blumschein, 2019). The main difference is that simulation-based environments are artefact-centred and have a clear focus aimed at the central role of an artefact in the form of a model for simulations. It is also important to stress the difference between simulation using and simulation building activities. The difference is clearly seen if a well-known analogy or the so-called "black box" model will be applied. Franko Landrisina (Landriscina, 2013), as opposed to a "black box" as a model of learning by using simulations, suggests a "glass box" as a model describing learning activities of simulationbuilding.

Another important issue to be considered is the problem of the cognitive opacity of simulation models. This problem, as refers to SCE, brings a new insight to the earlier discussed so-called "situated learning" approach (Brown et al., 1989; Laurillard, 2013). The situated environment should be designed 


\section{Scientific computing for STEM}

in a manner which enables using a set of "rendering" the model features, as well as in the form of instructional design tools that bring such features into the environment. This is an absolutely challenging task, as it also requires teacher expertise to be transformed into a set of instructions. Moreover, this requirement is based on the prediction that such expertise is presented explicitly, that is not a case as all knowledge is either tacit or rooted in tacit knowledge (Polanyi, 1966; Senker, 1995): "... these two are not sharply divided. While tacit knowledge can be possessed by itself, explicit knowledge must rely on being tacitly understood and applied. Hence all knowledge is either tacit or rooted in tacit knowledge".

It is important to stress, that knowledge but not skills are considered as "tacit". In spite of a seeming contradiction, namely, knowledge, related to cognitive concepts, involves such cognitive dimensions as schemata, paradigms, mental models, etc. (Senker, 1995). Is it possible to make this knowledge explicitly available? It could be possible by practical experience or interaction with experts (Senker, 1995) and with teachers in the context of educational environment. Therefore, the mediating role of a teacher becomes even more important. A teacher should focus not only on mediating the situated learning environment but also on transferring his personal and best practice expertise in the field of model-based simulations. At the same time, simulation-based learning involves an epistemic interplay among different kinds of students' mental models which are developed during simulation activities. Therefore, a well-designed learning process should be aware of the process of constructing students' mental models (Landriscina, 2009).

The main focus of education is on improving students' skills in creating simulation models. These skills should provide universal prerequisites for the complete educational environment. At the same time, the content of CS, information, and communication technology courses could be revised focusing on modelling and simulation solutions. Figure 1 presents an outline of the methodology in the form of a feature model.

The model by itself should be designed as a multifaceted model with emphasis on teaching students and using didactic approach which is based on DSR methodology requirements. The multifaceted feature of the model allows students to construct their knowledge in a constructionist manner, enabling students group work and collaborations and bringing gaming elements into learning. 




Figure 1. Feature model for DSR and SI centred pedagogy for grounding the learner's cognitive models in the form of a concept map

\section{Main design principles for the model-based scientific inquiry centred scientific computing introductory content}

The main points of SCE should be refocused on teaching the basic principles of model-based simulations and training the skills enabling students to develop model-based simulations. This means not narrowing but, on the contrary, widening the scope of the curricula. At the same time, this unifies and integrates 
the complete educational environment, enables the constructionist approach to learning, brings possibilities of gamification into the learning process. Designing the content, an integrated approach considering all phases of SI should be undertaken.

As an example, we provide a class of models, based on recurrent equations of the form:

$$
n+1=f(n, n-1, \ldots)
$$

is:

The simplest example is Fibonacci numbers. The recurrence definition of Fibonacci numbers

$$
F(n+1)=F(n-1)+F(n-2), N>2 ; F(1)=F(2)=1
$$

In spite of its simple form, these examples become a basis of the whole unit focused on modelling scientific problems, which are based on recurrences, including stochastic recurrences. First, a scientific problem, for example like analysis of the population growth problem (P) (Bryc, 1996; Heyde, 1981; Iosifescu et al., 2013) should be formulated. The recursive programming model could solve it. Therefore, to find a solution, students could develop a simple simulation in the form of a recursive program that calculates Fibonacci numbers. To facet the model, some additional feature should be incorporated. For example, the problem could be modified (P1) by asking about the time the population should be $k$ times bigger than the population of humans. Now, students should think about the improvement of the previous model and make a horizontal step in the educational design cycle. It could be so that recursive solution will not suite due to the lack of computational resources and this will force students to look for another solution as an explicit form of Fibonacci (P2) (Binet's formula): the next possible step is to introduce the Fibonacci primes. So the modified problem (P3) could be formulated as:

$$
F(n)=\frac{(1+\sqrt{5})^{n}-(1-\sqrt{5})^{n}}{2^{n} \sqrt{5}}
$$

the modification of (P2) with constraints on the population number allowing only prime Fibonacci values for the number of population. In such a case, students will be forced to implement parallelization techniques into their previously developed models.

The next step is to involve optimization and to modify the problem into the next form: $k(t) \rightarrow$ max within provided computational resources (P4). Students could be asked to represent the dependence $k(t)$ graphically. For better-prepared students, the emphasis on probability, stochastics (Papoulis \& Pillai, 2002) and analogues of Fibonacci series (P5) could be placed (Heyde, 1981; Iosifescu et al., 2013). The stochastic model of the evolution of populations on whose members undergo a phase of immaturity based on Fibonacci series could be presented (Iosifescu et al., 2013). Let $\xi_{i}(n), i \in N+, n \in N$ be independent identically distributed random variables of generating function:

$$
f(z)=\sum_{k \in N} p_{k} z^{k}, 0<m=f^{\prime}(1)<\infty
$$

Let $X(0)$ and $X(1)$ be independent random variables that are also independent of $\xi$. The stochastic Fibonacci model is defined as follows (Iosifescu et al., 2013):

$$
X(n+2)-X(n-1)=\left\{\begin{array}{l}
\sum_{l=1}^{X(n)} \xi_{l}(n), \text { if } X(n)>0, n \in N \\
0, \text { if } X(n)=0, n \in N .
\end{array}\right.
$$

Obviously, the particular case $\xi_{i}(n)=X(0)=X(1)=1$ a.s., $i \in N+, n \in N$ is nothing but the Fibonacci sequence. This allows introduction to stochastic experiments and stochastic modelling 
including stochastic processes and the MC method (Thompson et al., 1985; Toral \& Colet, 2014). As an example, the next problem (P6) to prove ergodicity of the described stochastic process (Papoulis \& Pillai, 2002) could be formulated. The described process is considered as mean-square ergodic in the first moment if:

$$
\lim _{n \rightarrow \infty} \frac{\sum_{0}^{n} X(n)}{n}=E[X(n)]
$$

where $E[X(n)]$ is the constant mean. The ergodicity in the second moment could be studied as well:

$$
\lim _{n \rightarrow \infty} \frac{\left.\sum_{0}^{n}[X(n+1)-E[X(n)])(X(n)-E[X(n)])\right]}{n}=E[(X(n+1)-E[X(n)])(X(n)-E[X(n)])]
$$

Such modifications or "faceting" of the problem introduce gamification features into the learning process and facilitates the constructionist approach to learning. It is important to stress that this simply formulated example incorporates the main features of the model-centred scientific inquiry-based education as focus on model-based simulations and seamless approach to theoretical backgrounds. In the process of designing a simulation model, students are forced to practice using design cycles and other DSR analytic techniques starting from formulating the hypothesis and providing working solutions for simulations. At the same time, the multifaceted feature of the model allows students to construct their knowledge in the constructionist manner, enabling students group work and collaborations and bringing gaming elements into learning. Figure 2 presents the summary of the presented design principles.

\section{Technological domain model}

Technological domain model is of primary importance. First, technology plays an important role for providing a platform for experiments with computers, including modelling, simulation and parallelization topics; second, the technology itself is a topic to be included in to the curriculum. Technological domain consists of several major parts like: hardware platforms for computations; software tools for implementation of algorithms; software engineering topics and technologies.

Hardware platforms for calculations include various computational platforms. Here, for instance, important are the big data processing feature and parallelization enabling features: the type of the processing unit (usually Complex Instruction Set Computing (CISC)); the type of the computational architecture (as related to the topic of parallelization); Details of various processing architectures: SISD, SIMD, Multiple Instructions, Single Data (MISD), MIMD; Details of MIMD architectures: Uniform Memory Access (UMA), Non Uniform Memory Access (NUMA) solutions; Details of hybrid HPCC architecture. 


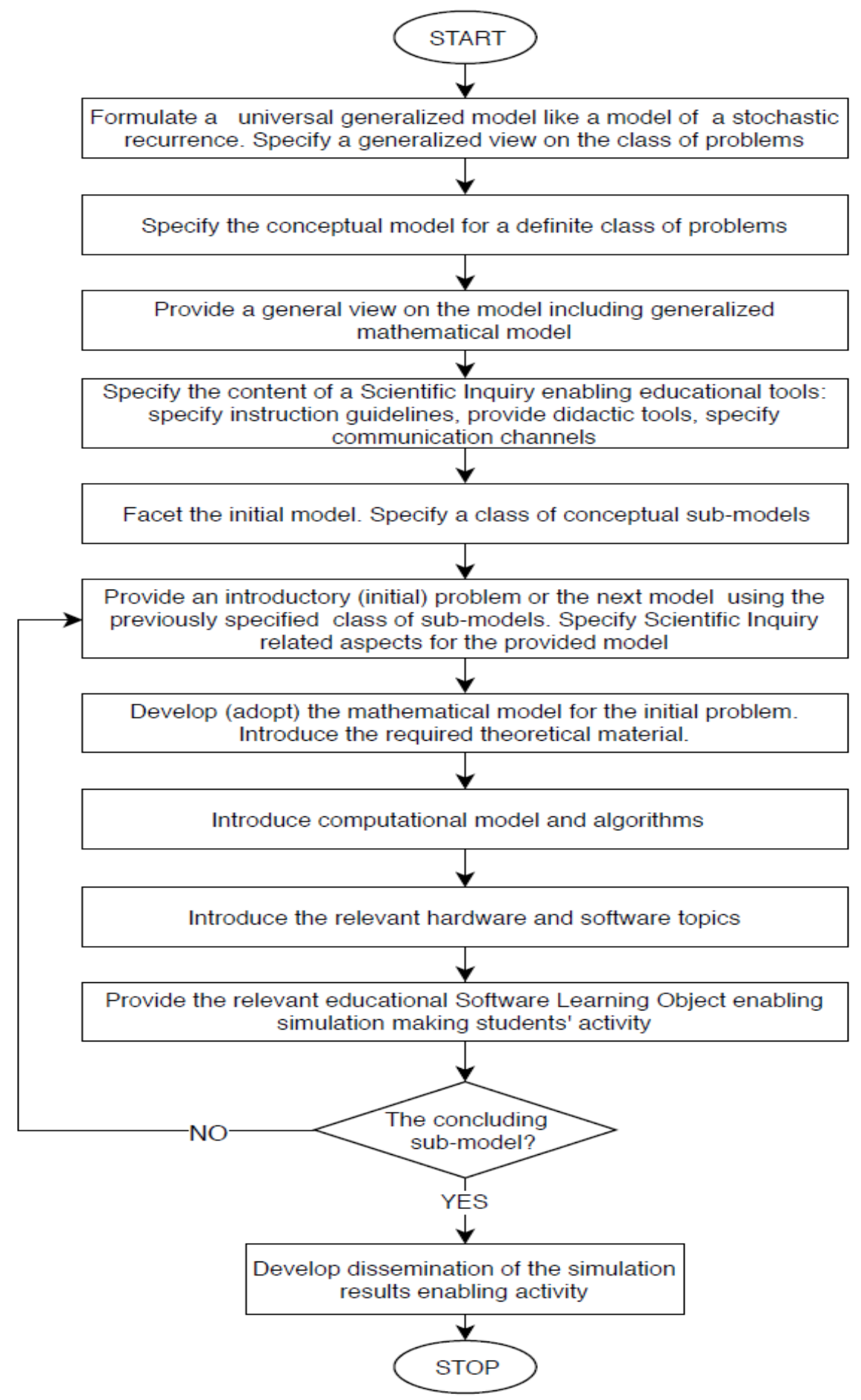

Figure 2. Summary of the design principles for the model based SI centred learning resources

Software tools for implementation of algorithms include parallelization specific software tools, e.g. shared memory parallelization tools; distributed memory parallelization tools; platforms specific operation systems; platforms specific command languages; SC specific tools: randomization tools, matrix and vector computations; big-data visualization tools; platform (computation, visualization, simulation) specific programming languages and tools.

Software engineering topics and technologies include software development methods. This is especially relevant for implicit parallelization techniques and techniques based on the functional 
approach to programming. Such methods include: model-based approach to software engineering; software engineering approaches to scientific computing methods and algorithms; software engineering approaches to big data processing including data storage and visualization aspects.

\section{Implementation of the models}

The following examples are more complex and use queueing networks and stochastics. Basic principles of queueing networks (Gautam, 2012; Mercer \& Newell, 1972; Nelson, 2012) are easy to understand and could become a foundation for various problems and simulation experiments. Python for modelbased and simulation-centred education is presented in (Dolgopolovas et al., 2014). The model of Stochastic simulations of queueing systems using the $C$ is presented in (Dolgopolovas et al., 2015).

\section{Generalized feature model}

Summing up, the feature model could be implemented as a concept map diagram. The reasoning schemes used give an outline of concepts and meanings used during the assertions: SCE: revision of definitions (the main focus is on SI and research, not on content); model centred approach; from conceptual model to computer model (may be in the form of educational software and a possible approach is to implement software in the form of a learning object); teaching how to do research; teaching SI by how to make models and conduct experiments with models; teaching of how to make model-based simulations; seamless approach to theoretical prerequisites; DSR for improvement of models (as a teaching method); educational task: improvements of the model-based simulation (with the aim to find a solution to the scientific problem); students as researchers; educators provide an artificial environment for this "primary" research; main focus on models and simulations (on artefacts); inquiry-based, constructionist, and research-based education; DSR-based education.

Interdisciplinary education: focus on research in the field of interest; doing research; solving scientific problems by SI; making scientific model-based simulation.

The research context: practical examples of implementations; DSR formalisms; evaluation; dissemination; published papers. The concept map of the related features is presented in Figure 3. The list of concepts covered in the research include: Cognitive artefact; Case Studies; Computational Model; Conceptual Model; DSR; Dissemination; Educational technology; Evaluation of models; Formalization; Computer Hardware; Instructional Design; Instructional Patterns; Interdisciplinary University Research; Learning Object; Mathematical Model; Model (in general); Model-based Scientific Simulations; Pedagogical Patterns; Research methods; Grounding; Sample Software; SI; Simulational Reasoning; Teaching Research methods; Teaching Interdisciplinary Curriculum; Teaching Methods; Teaching SC; Teaching STEM, Engineering; Theoretical prerequisites. 


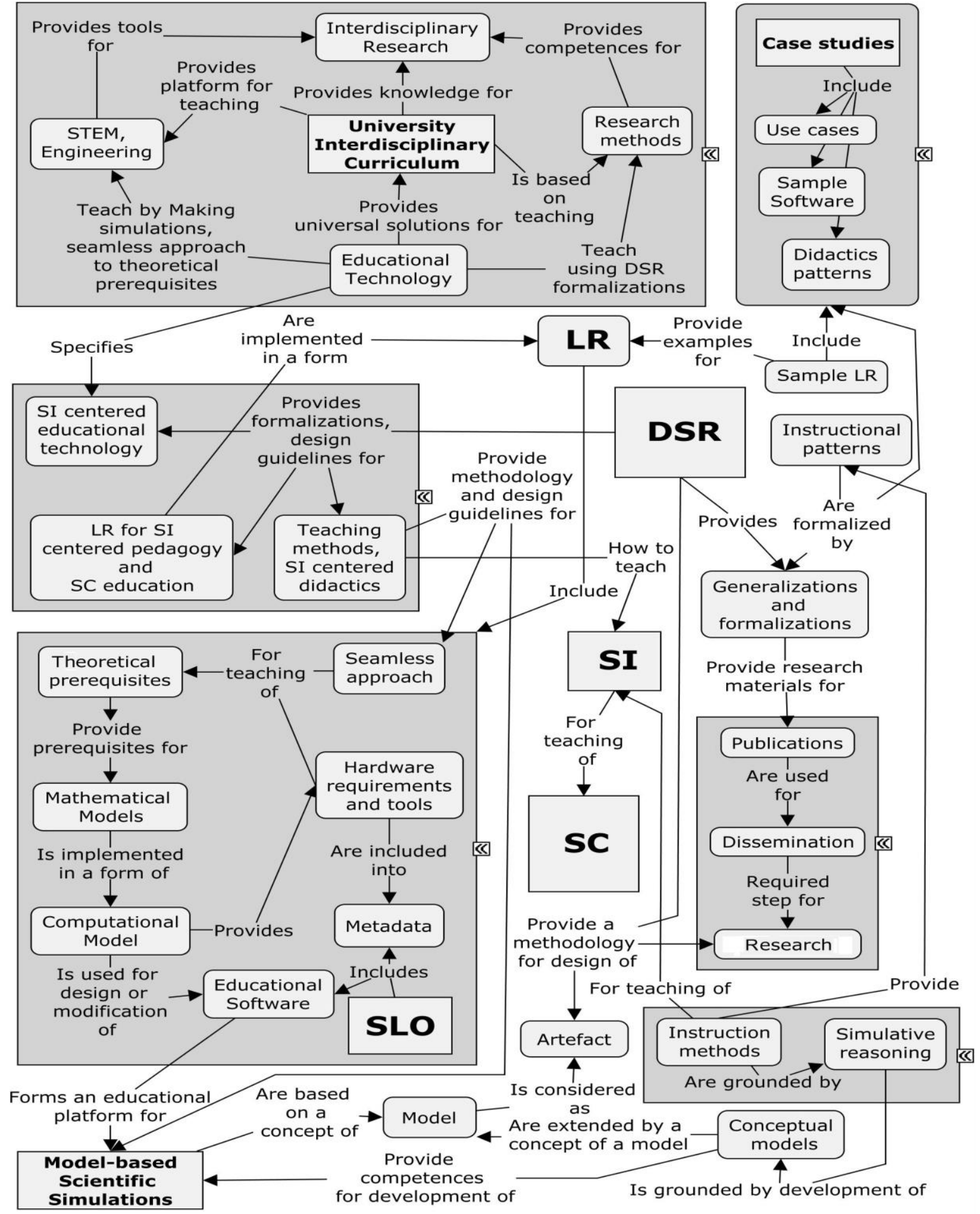

Learning Resources (LR); Scientific Inquiry (SI); Scientific Computing (SC); Design Science Research (DSR); Software Learning Object (SLO); Science, Technology, Engineering, Mathematics (STEM)

Figure 3. Generalized feature model in the form of a concept map

\section{Discussion and conclusion}

The research focuses on a holistic view of scientific computing education and provides the synthesised and structured literature survey and development of design and integration principles for application 
and integration of the educational resources (software learning objects) for teaching scientific computing.

The TPACK model provides a relevant framework for systematising research context in the form of a definite structure. This serves as a meta-structure for research context focusing on the three major areas: educational technology, instructional design and didactic aspects of teaching SC.

The importance of pedagogical ideas of integration and seamless approach to scientific computing education is stressed. As the discipline that could potentially cover different fields of science, with a variety of theoretical backgrounds and traditions, a unifying approach, implemented within an educational institution like a university, could provide complex foundations aimed, besides fieldspecific knowledge, at improving scientific inquiry, computational literacy, and engineering skills. At the same time, such unifying approach provides a solid background for interdisciplinary research activities, and this is of primary importance for modern science, technology, and education in these fields.

The context provides a clear set of its features, enabling further implementation of domainspecific models. These features are specified as follows: (1) interdisciplinarity enabling features, important for specifying the educational policy in general; (2) constructionist educational approaches and the relevant features, enabling proper direction for positioning of educational approaches and theories in general, design and specification of instructional design approaches in particular; (3) modelbased approaches and simulation-centred approaches, clarifying the directions for development of constructionist educational methods; (4) software learning objects, clarifying the description and specifications for learning objects as related to CS education in general and SLOs as related to SCE in particular; (5) specification of scientific inquiry related context, providing a background for modelbased and simulation-centred approaches; (6) specification of Design Science Research and its features within the context of the research, enabling further development and implementation of the applications of the DSR methodology in the research context and the domains in the study.

The approach presented in this manuscript provides constructionist project-based learning methodology. The aim of the presented methodology is to support the universal approach to the university STEM education, thus enabling a common basis for interdisciplinarity and innovations. Abduction and circumscription should be introduced into the practice of the educational process. This is important for a modern scientific environment as this enables creations and scientific innovations. At the same time, such approaches as model-based approaches to learning and instruction are presented in the form of research pedagogy for university STEM education. The model-based approach provides the basis for education through the development of model-based scientific simulations, improving educational research methods and project-based educational approaches. DSR delivers formalization in the form of universal teaching methods. Based on these considerations, students can act as part of an interdisciplinary team of researchers creating hypotheses, developing simulations, evaluating results, and utilising DSR tools and methods. Teachers must provide an educational research environment in the form of pre-designed models, relevant instructional approaches, and corresponding seamless theoretical foundations.

Such a unifying approach, in the form of the developed design and integration principles, provides a base for modernization of existing and creation of innovative university educational programs, enhancing diversity and interdisciplinarity in research and modern university education. The presented educational solutions are aimed at university STEM education that is focused on enhancing interdisciplinary and innovations in the modern university curricula. Educational solutions implement a scientific inquiry centred approach and provide a set of practical educational techniques and unifying teaching methods. Relying on Peirce pragmatism and principles of embodied cognition, this study suggests a bridge from the cognitive theoretical constructions to practical educational techniques and methods, which are pragmatically useful and applicable for educational practitioners. The presented approach is based on such theoretically well-grounded and practically effective solutions as the Design Science Research methodology, a model-centred approach to instructional design, model-based teaching methods, problem-solving and constructionist didactic approaches. For the purpose of this study, scientific inquiry centred approach is understood as an educational process of designing (developing, testing, evaluating, and improving) model-based scientific computer simulations. Computer simulations, underlying software, computational and conceptual models as cognitive 
artefacts allow the Design Science Research methodology to be implemented in the form of a practical teaching tool. An appropriate educational environment that is based on pre-designed multifaceted models and a seamless approach to theoretical prerequisites is introduced.

The main practical input of the presented research is not only the presented feature model that can be used to develop interdisciplinary scientific computing course, fostering scientific inquiry, but also the process of the model development.

Unless we address higher school (university level studies) in this article due to the possible complexity of models to be developed by the students as researchers, the proposed approach can be successfully adapted for the middle and high school levels by defining appropriate knowledge domain.

\section{Declaration of Conflicting Interests}

The author declared no potential conflicts of interest with respect to the research, authorship, and/or publication of this article.

\section{References}

Barsalou, L. W. (2008). Grounded Cognition. Annual Review of Psychology, 59(1), 617-645. https://doi.org/10.1146/annurev.psych.59.103006.093639

Barsalou, L. W. (2010). Grounded cognition: Past, present, and future. Topics in Cognitive Science, 2(4), 716-8765.

Bell, T., Alexander, J., Freeman, I., \& Grimley, M. (2009). Computer science unplugged : school students doing real computing without computers. New Zealand Journal of Applied Computing and Information Technology, 13(1), 20-29.

Boboc, M. (2012). The Postmodern Curriculum in a Modern Classroom. International Journal of Education, 4(1), 142. https://doi.org/10.5296/ije.v4i1.1167

Boix-Mansilla, V. (2010). Learning to synthesize: the development of interdisciplinary understanding. The Oxford Handbook of Interdisciplinarity, 288-309.

Brown, J. S., Collins, A., \& Duguid, P. (1989). Situated Cognition and the Culture of Learning. Educational Researcher, 18(1), 32-42. https://doi.org/10.3102/0013189X018001032

Bryc, W. (1996). Applied Probability and Stochastic Processes. University of Cincinnati.

Campbell, L. M. (2005). Overcoming obstacles to interdisciplinary research. Conservation Biology, 19(2), 574-577. https://doi.org/10.1111/j.1523-1739.2005.00058.x

Collier, P. (2017). The new pragmatism. In TLS - The Times Literary Supplement (Vols. 2017-Janua, Issue 5939). Routledge. https://doi.org/10.5860/choice.48-2608

Davies, M., \& Devlin, M. (2007). Interdisciplinary higher education: Implications for teaching and learning. In University of Melbourne: Centre for the Study of Higher Education. Centre for the Study of Higher Education.

Dawe, G., Jucker, R., \& Martin, S. (2005). Sustainable Development in Higher Education: Current Practice and Future Developments Developments. Higher Education.

DeZure, D. (2010). Interdisciplinary pedagogies in higher education. The Oxford Handbook of Interdisciplinarity, Chapter 26, 372. https://doi.org/10.1093/oxfordhb/9780198733522.013.45

Dolgopolovas, V., Dagienė, V., Jasutė, E., \& Jevsikova, T. (2019). Design Science Research for Computational Thinking in Constructionist Education: A Pragmatist Perspective. Problemos, 95, 144-159. https://doi.org/10.15388/10.15388/Problemos.95.12 
Dolgopolovas, V., Dagienè, V., Minkevičius, S., \& Sakalauskas, L. (2014). Python for scientific computing education: Modeling of queueing systems. Scientific Programming, 22(1), 37-51. https://doi.org/10.3233/SPR-140377

Dolgopolovas, V., Dagienè, V., Minkevičius, S., \& Sakalauskas, L. (2015). Teaching Scientific Computing: A Model-Centered Approach to Pipeline and Parallel Programming with C. Scientific Programming, 2015(2), 223-240. https://doi.org/10.1155/2015/820803

Dolgopolovas, V., Jevsikova, T., Dagiené, V., \& Savulioniené, L. (2016). Exploration of computational thinking of software engineering novice students based on solving computer science tasks. International Journal of Engineering Education, 32(3), 1107-1116.

Gautam, N. (2012). Analysis of queues: Methods and applications. In Analysis of Queues: Methods and Applications. CRC Press. https://doi.org/10.1201/b11858

Goldkuhl, G. (2012). Pragmatism vs interpretivism in qualitative information systems research. European Journal of Information Systems, 21(2), 135-146. https://doi.org/10.1057/ejis.2011.54

Golub, G. H., \& Ortega, J. M. (1993). Scientific computing: an introduction with parallel computing. In Choice Reviews Online (Vol. 30, Issue 10). Elsevier. https://doi.org/10.5860/choice.30-5637

Hevner, A. R. (2004). A Three Cycle View of Design Science Research A Three Cycle View of Design Science Research. Scandinavian Journal of Information Systems, 19(2), 87-92.

Heyde, C. C. (1981). On Fibonacci (or lagged Bienaymé-Galton-Watson) branching processes. Journal of Applied Probability, 18(3), 583-591. https://doi.org/10.2307/3213313

Holley, K. A. (2009). Understanding interdisciplinary challenges and opportunities in higher education. Innovations in Higher Education, 34(2), 1-131. https://doi.org/10.1002/aehe.3502

Horvath, C. P., \& Forte, J. M. (2011). Critical thinking. In Critical Thinking. https://doi.org/10.5840/teachphil200326337

Iosifescu, M., Limnios, N., \& Oprişan, G. (2013). Branching Models. In Introduction to Stochastic Models (pp. 227-313). https://doi.org/10.1002/9781118623220.ch6

Jadrich, J. X., \& Bruxvoor, C. (2015). Learning and Teaching Scientific Inquiry: Research and Applications. In Learning and Teaching Scientific Inquiry: Research and Applications. NSTA press. https://doi.org/10.2505/9781936137220

Juškevičiene, A., \& Dagiene, V. (2018). Computational thinking relationship with digital competence. Informatics in Education. https://doi.org/10.15388/infedu.2018.14

Justi, R. S., \& Gilbert, J. K. (2002). Modelling, teachers' views on the nature of modelling, and implications for the education of modellers. International Journal of Science Education, 24(4), 369-387. https://doi.org/10.1080/09500690110110142

Klein, J. T. (1990). Interdisciplinarity: History, theory, and practice. Wayne state university press.

Klein, J. T. (1999). Mapping Interdisciplinary Studies. The Academy in Transition. Association of American Colleges and Universities. http://files.eric.ed.gov/fulltext/ED430437.pdf

Landriscina, F. (2009). Simulation and learning: The role of mental models. In Journal of E-Learning and Knowledge Society (Vol. 5, Issue 2, pp. 23-32). Springer. https://doi.org/10.1007/978-14419-1428-6_1874

Landriscina, F. (2013). Simulation and learning: A model-centered approach. In Simulation and learning: A model-centered approach.

Lattuca, L. R. (2001). Creating interdisciplinarity: Interdisciplinary research and teaching among college and university faculty. Vanderbilt university press.

Laurillard, D. (2013). Rethinking university teaching: A conversational framework for the effective use of learning technologies. In Rethinking University Teaching: A Conversational Framework 
for the Effective Use of Learning Technologies. Routledge. https://doi.org/10.4324/9781315012940

Magnani, L. (1999). Model-Based Creative Abduction. In Model-Based Reasoning in Scientific Discovery (pp. 219-238). Springer. https://doi.org/10.1007/978-1-4615-4813-3_14

Magnani, L. (2009). Abductive Cognition: The Epistemological and Eco-Cognitive Dimensions of Hypothetical Reasoning. In Cognitive Systems Monographs. https://doi.org/10.1017/CBO9781107415324.004

McCarthy, J. (1981). Circumscription - a form of non-monotonic reasoning. In Readings in Artificial Intelligence (pp. 466-472). Elsevier.

Mercer, A., \& Newell, G. F. (1972). Applications of Queueing Theory. In Operational Research Quarterly (1970-1977) (Vol. 23, Issue 4). Springer Science \& Business Media. https://doi.org/10.2307/3007978

Mishra, P. (2019). Considering Contextual Knowledge: The TPACK Diagram Gets an Upgrade. In Journal of Digital Learning in Teacher Education (Vol. 35, Issue 2, pp. 76-78). https://doi.org/10.1080/21532974.2019.1588611

Mitrevski, B. (2019). Teaching critical thinking and problem solving in physics. AIP Conference Proceedings, 2075(2), 90. https://doi.org/10.1063/1.5091398

Molenda, M., Reigeluth, C., \& Miller-Nelson, L. (2013). Instructional design theories and models: An overview of their current status. In Instructional Design (pp. 574-578).

http://scholar.google.com.my/scholar?q=instructional+design+model\&btnG=\&hl=en\&as_sdt=0, 5\&as_ylo=2010\&as_yhi $=2013 \# 0$

Nelson, B. L. (2012). Stochastic modeling: analysis and simulation. Courier Corporation.

Newell, W. H. (2001). A Theory of Interdisciplinary Studies. Issues in Integrative Studies, 25(19), 125.

O’Neill, G., Fraser, S. P., Bosanquet, A. M., Need, T., Scale, C., Dillon, J. T., Engaging, K., Barradell, S., Barrie, S., Peseta, T., Barnett, R., Parry, G., \& Coate, K. (2018). Curriculum Design in Higher Education : Theory To Practice. In Journal of Curriculum Studies. https://doi.org/10.1021/ja0733282

Papoulis, A., \& Pillai, S. U. (2002). Probability, random variables, and stochastic processes. Tata McGraw-Hill Education.

Peirce, C. S., \& Houser, N. (1993). The essential Peirce: selected philosophical writings. v.1: 18671893. In Choice Reviews Online (Vol. 31, Issue 01). Indiana University Press. https://doi.org/10.5860/choice.31-0230a

Pezzulo, G., Barsalou, L. W., Cangelosi, A., Fischer, M. H., McRae, K., \& Spivey, M. J. (2013). Computational grounded cognition: A new alliance between grounded cognition and computational modeling. In Frontiers in Psychology (Vol. 3, Issue JAN, pp. 612 @ 1664-1078). https://doi.org/10.3389/fpsyg.2012.00612

Polanyi, M. (1966). The logic of tacit inference. Philosophy, 41(155), 1-18. https://doi.org/10.1017/S0031819100066110

Pring, R. (2007). John Dewey: Continuum Library of Educational Thought. London: Continuum.

Romiszowski, A. J. (2016). Designing instructional systems: Decision making in course planning and curriculum design. In Designing Instructional Systems: Decision Making in Course Planning and Curriculum Design. Routledge. https://doi.org/10.4324/9780203063446

Seel, N. M., \& Blumschein, P. (2019). Modeling and Simulation in Learning and Instruction: A Theoretical Perspective. Model-Based Approaches to Learning: Using Systems Models and Simulations to Improve Understanding and Problem Solving in Complex Domains, 2-14. https://doi.org/10.1163/9789087907112_003 
Senker, J. (1995). Tacit knowledge and models of innovation. Industrial and Corporate Change, 4(2), 425-447. https://doi.org/10.1093/icc/4.2.425

Snyder, L. G., \& Snyder, M. J. (2008). Teaching critical thinking and problem solving skills. The Delta Pi Epsilon Journal.

Spelt, E. J. H., Biemans, H. J. A., Tobi, H., Luning, P. A., \& Mulder, M. (2009). Teaching and learning in interdisciplinary higher education: A systematic review. Educational Psychology Review, 21(4), 365-378. https://doi.org/10.1007/s10648-009-9113-z

Stein, B., Haynes, A., Redding, M., Ennis, T., \& Cecil, M. (2007). Assessing critical thinking in STEM and beyond. Innovations in E-Learning, Instruction Technology, Assessment, and Engineering Education. https://doi.org/10.1007/978-1-4020-6262-9_14

Thagard, P. (2010). How brains make mental models. In Studies in Computational Intelligence (Vol. 314, pp. 447-461). Springer. https://doi.org/10.1007/978-3-642-15223-8_25

Thagard, P., \& Stewart, T. C. (2011). The AHA! experience: Creativity through emergent binding in neural networks. Cognitive Science, 35(1), 1-33. https://doi.org/10.1111/j.15516709.2010.01142.x

Thompson, W. A., Taylor, H. M., \& Karlin, S. (1985). An Introduction to Stochastic Modeling. In Journal of the American Statistical Association (Vol. 80, Issue 390). Academic press. https://doi.org/10.2307/2287941

Toral, R., \& Colet, P. (2014). Stochastic Numerical Methods: An Introduction for Students and Scientists. Wiley.

Wing, J. M. (2008). Computational thinking and thinking about computing. Philosophical Transactions of the Royal Society A: Mathematical, Physical and Engineering Sciences, 366(1881), 3717-3725. https://doi.org/10.1098/rsta.2008.0118

Wooster, J. S., \& Papert, S. (1982). Mindstorms: Children, Computers, and Powerful Ideas. The English Journal, 71(8), 60. https://doi.org/10.2307/816450 